\title{
Permeability enhancement from a hydraulic stimulation imaged with Ground Penetrating Radar
}

\section{Journal Article}

\section{Author(s):}

Shakas, Alexis (D); Maurer, Hansruedi; Giertzuch, Peter-Lasse; Hertrich, Marian; Giardini, Domenico; Serbeto, Francisco; Meier, Peter

Publication date:

2020-09-16

Permanent link:

https://doi.org/10.3929/ethz-b-000437912

Rights / license:

In Copyright - Non-Commercial Use Permitted

Originally published in:

Geophysical Research Letters 47(17), https://doi.org/10.1029/2020gl088783

Funding acknowledgement:

691728 - Demonstration of soft stimulation treatments of geothermal reservoirs (SBFI) 


\section{Geophysical Research Letters}

\author{
RESEARCH LETTER \\ 10.1029/2020GL088783 \\ Key Points: \\ - First-time direct imaging of \\ stimulation-enhanced permeability \\ in fractured rock \\ - GPR difference imaging reveals the \\ DFN enhanced by the stimulation \\ - Information gained about the \\ stimulation volume and radial \\ extent of flow
}

Supporting Information:

- Supporting Information S1

Correspondence to:

A. Shakas,

alexis.shakas@sccer-soe.ethz.ch

Citation:

Shakas, A., Maurer, H., Giertzuch,

P.-L., Hertrich, M., Giardini, D.

Serbeto, F., \& Meier, P. (2020).

Permeability enhancement from a

hydraulic stimulation imaged with

Ground Penetrating Radar. Geophysical

Research Letters, 47, e2020GL088783.

https://doi.org/10.1029/2020GL088783

Received 11 MAY 2020

Accepted 16 AUG 2020

Accepted article online 30 AUG 2020

\section{Permeability Enhancement From a Hydraulic Stimulation Imaged With Ground Penetrating Radar}

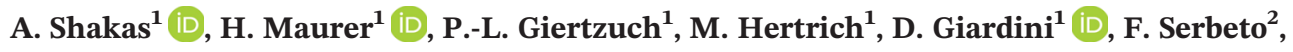 \\ and P. Meier ${ }^{2}$ \\ ${ }^{1}$ Department of Earth Sciences, ETH Zurich, Zurich, Switzerland, ${ }^{2}$ Geo-Energie Suisse AG, Zurich, Switzerland
}

\begin{abstract}
We present evidence of permeability enhancement from hydraulic stimulation experiments in fractured crystalline rock. A total of $9.49 \mathrm{~m}^{3}$ was injected in two fractured intervals of a $300 \mathrm{~m}$ long borehole. Repeated Ground Penetrating Radar (GPR) measurements in the same borehole were carried out prior to and following the stimulation. The initial measurements revealed fractures in the vicinity of the borehole that could be traced up to distances of $50 \mathrm{~m}$ away. The data measured post-stimulation were used in a difference-imaging approach to illuminate changes in the GPR reflections caused by the stimulations. The changes delineate the enhancement of a large and complex fracture network. These changes likely correspond to changes in local aperture, thus permeability. Our results indicate that borehole GPR yields unique information on subtle changes in hydraulic properties within a relatively large volume and provides a new perspective on the characterization and monitoring of deep geothermal reservoirs.
\end{abstract}

Plain Language Summary Deep geothermal reservoirs are a renewable and carbon-neutral source of energy that is globally underutilized. Their principle is to efficiently extract heat energy from the Earth by circulating a fluid within a deep reservoir. Oftentimes, reservoirs need to be Engineered (or Enhanced), leading to the term Engineered Geothermal Systems (EGS). EGS rely on enhancing a reservoir's permeability, its ability to allow for fluid flow. Geophysical remote sensing techniques are useful in illuminating changes in properties of an EGS, and in monitoring its evolution. In crystalline bedrock environments, borehole Ground Penetrating Radar (GPR) is especially useful in mapping contrasts between rock and water. Here, we present results from a hydraulic stimulation experiment that aimed at enhancing a reservoir's permeability by injecting water in existing fractures. Using GPR single-hole reflection imaging, we were able to map existing fractures within a relatively large volume. By repeating the measurements after the stimulations, we were able to detect changes in their reflectivity that most likely arise from permeability changes caused by the stimulation. The ability of GPR borehole measurements to image changes of the hydraulic properties in such high resolution offers a new and exciting perspective for characterizing and monitoring EGS.

\section{Introduction}

Increasing the use of renewable energy is essential for a sustainable future. A powerful option to achieve this goal includes geothermal energy, which has been traditionally exploited in regions with high natural geothermal gradients and suitable hydrothermal reservoirs, such as Iceland (Fridleifsson, 2001). A promising approach to utilize deep geothermal energy more widely is offered by Engineered (or Enhanced) Geothermal Systems (EGS). EGS are heat exchange reservoirs created in low-permeability formations that are otherwise unexploitable (Hirschberg et al., 2015). The permeability of such reservoirs is "engineered" or "enhanced" through hydraulic stimulation. In conventional EGS, a fluid (often water) is injected at high pressure in a stimulation well to either enhance the permeability of existing fractures or generate new fractures. The fluid will then flow through these fractures into another (production) well and absorb heat along its flow path. The accumulated heat is later converted to electrical energy.

The primary aim of hydraulic stimulation is to enhance the permeability of an EGS. This is necessary in reservoirs where the permeability of the host rock is negligible, such as crystalline basement rocks. In such settings, the main conduits for fluid flow are fractures (Council, 1996; Sharp, 2014) that act as discrete entities in a more or less homogeneous matrix. This leads to the conceptual model of a Discrete Fracture
(C)2020. American Geophysical Union. All Rights Reserved. 
Network (DFN). While the connectivity of fractures plays a major role for flow within a DFN, arguably, the most important parameter for describing fluid flow and transport through a fracture is the fracture aperture. Local aperture (i.e., the separation between two rough fracture surfaces) can be linked directly to permeability through the cubic law (Nicholl et al., 1999). The success of the cubic law in describing flow has been studied theoretically and experimentally in both laboratory and field work (Klimczak et al., 2010; Oron \& Berkowitz, 1998; Witherspoon et al., 1980). Knowledge of the aperture distribution in an EGS is thus fundamental for describing its permeability.

Observing and quantifying the effect of a hydraulic stimulation, let alone monitoring it over time, has been proven to be an extremely challenging task. For this, geophysical remote sensing methods can be used. The primary and most commonly employed technique is seismics. One can either exploit the naturally induced (passive) seismicity during the creation of a fracture (e.g., Shapiro \& Dinske, 2009), or seismic waves from a suitable (active) artificial source can be employed. Fluid induced seismic signatures have been used successfully to characterize fluid propagation during hydraulic-fracturing (Shapiro et al., 2002, 2006; Rutledge \& Phillips, 2003), to monitor the stress state of a reservoir (Calò et al., 2014), assess transmissivity changes (Jalali et al., 2018), and they are routinely used to monitor hydraulic stimulation experiments (Cladouhos et al., 2013; Dorbath et al., 2009; Häge et al., 2013; Julian et al., 2009).

Nevertheless, passive seismicity can arise from a multitude of dynamic processes, including creation of new fracture volumes, fracturing fluid loss, interaction with the pore space or pressure diffusion into the surrounding rock (Shapiro et al., 2006). To date, there is no direct (physical) link between passive seismic signatures and the permeability enhancement of a fracture or fracture network. Therefore, most studies focus on defining proxies to permeability (Delepine et al., 2004; Vogt et al., 2012). To further complicate the problem, it has been noted that a significant portion of the fractures may form aseismically during hydraulic stimulation (Amann et al., 2018; Jeanne, Rutqvist, Rinaldi, et al., 2015). Active (artificial) seismic sources offer an interesting alternative option, because they can serve to illuminate certain properties of an EGS. As shown by Charléty et al. (2006), changes within an EGS reservoir can cause variations in the seismic velocity. These include mechanical properties (Jeanne, Rutqvist, Hutchings, et al., 2015) or increased fluid pressure and rock deformation (Doetsch et al., 2018). Still, uncertainties remain high as to which processes govern these changes, and interpretations are thus ambiguous.

Electromagnetic (EM) geophysical methods are also available for characterizing EGS reservoirs (Börner et al., 2015; Spichak \& Manzella, 2009). One main advantage of EM methods is that there exist quantitative relationships between the electrical properties of the reservoir and the state variables of interest, namely temperature and presence of fluids (Thiel, 2017). In practice, magnetotellurics (MT) is often used, primarily due to its large penetration depth (often several kilometers) and its use of naturally occurring sources. MT has been used to characterize EGS (MacFarlane et al., 2014) and also in a time-lapse approach to monitor fluid injection and propagation (Abdelfettah et al., 2018; Peacock et al., 2012). MT offers some benefits compared to its seismic alternatives, but due to the diffusive nature of the EM fields and the very low frequencies involved, the method lacks spatial resolution.

GPR combines the advantages of seismic and diffusive EM methods. The high-frequency GPR waves offer a high spatial resolution, and the governing material properties (dielectric permitivity and electrical conductivity) can be linked directly to quantities of interest, such as temperature and the presence of water. The GPR reflection response has been often analyzed using a homogeneous model for a fracture by exploiting analytical solutions (Deparis \& Garambois, 2009; Tsoflias \& Hoch, 2006), but GPR reflections carry also information on aperture variations along a fracture down to sub-wavelength resolution (Shakas \& Linde, 2017). In fact, apertures that are several orders of magnitude smaller than the source dominant wavelength are detectable (Dorn et al., 2012; Markovaara-Koivisto et al., 2014; Shakas \& Linde, 2017; Tsoflias \& Hoch, 2006). In time-lapse mode, GPR has been used to infer processes such as fluid flow and transport of saline tracers (Dorn et al., 2011; Shakas et al., 2016; Tsoflias et al., 2015) or fracture opening caused by pumping (Tsoflias et al., 2001). This implies that changes in the aperture distribution of a fracture, due to hydraulic stimulation, should also be visible.

Despite the amenable properties of GPR, this technique has been rarely applied in actual EGS reservoirs, which is primarily due to the lack of appropriate GPR borehole equipment. This is unfortunate because 
GPR has the potential to offer unprecedented high-resolution images of DFN's in EGS reservoirs, and there seem to be no inherent technical limitations that preclude appropriate GPR instruments to be built.

In this contribution, we demonstrate the potential power of GPR for EGS applications. For this purpose, we present results from a time-lapse GPR survey that accompanied a hydraulic stimulation experiment. It was performed in the newly founded Bedretto Underground Laboratory for Geoenergies (BULG). With the exception of the temperature conditions, BULG offers a geological environment that mimics a realistic EGS reservoir. Our results indicate that GPR borehole data offer valuable information on the fracture geometry and changes of the fracture properties caused by hydraulic stimulations.

\section{Experimental Setup}

BULG is located in the southern Swiss Alps, at about $2 \mathrm{~km}$ horizontal distance in a $5.2 \mathrm{~km}$ long abandoned tunnel (https://www.bedrettolab.ethz.ch/home/). The laboratory is embedded within the Rotondo Granite intrusion of the Gotthard Massif, and it is covered by more than $1 \mathrm{~km}$ of granitic overburden (Figure 1a). Here, large-scale experiments are currently set up, aimed at better understanding the physical processes associated with an EGS reservoir. In contrast to actual EGS sites, BULG offers the unique opportunity to perform in situ studies within the reservoir volume.

From a hydrologic perspective, the BULG is fully contained below the water table and all open fractures are water filled. There are several hydraulically conductive fractures that intersect the drilled boreholes with often considerable outflow of several liters per minute. Therefore, all the boreholes are water filled. Prior hydraulic tests in the stimulated region have indicated very low (for the shallower interval) and no measurable (for the deeper interval) transmissivity. These findings are summarized in Table S1, found in the supporting information.

Three characterization boreholes (CB1: $302 \mathrm{~m}$, CB2 $222 \mathrm{~m}$, and CB3: $190 \mathrm{~m}$ ) were drilled during an initial phase (Figure $1 \mathrm{~b}$ ). Based on borehole acoustic and optical logging results, an initial test stimulation was designed and performed in CB1 by Geo-Energie Swiss (GES). The stimulation intervals are denoted with black bars in Figure 1b. For the first stimulation, double packers were used to seal the interval between 288.5 and $298.5 \mathrm{~m}$, and 4,937 L were injected. Immediately after this first stimulation, the packers were moved to stimulate the interval between 264 and $274 \mathrm{~m}$, and 4,552 L were injected. The stimulations were performed with ambient water, obtained on-site from the natural outflow of the tunnel. They were intended to open the visible but not hydraulically conductive fractures within this interval.

Three single-hole GPR surveys were carried out, namely, (i) 55 days prior to, (ii) 6 days after, and (iii) 12 days after the stimulations. During the period between the first survey and the stimulation, the boreholes were primarily kept closed. We employed $100 \mathrm{MHz}$ Mala borehole antennas that were rigidly connected to each other with a separation of $2.7 \mathrm{~m}$. This antenna setup was lowered to the bottom of borehole CB1. Subsequently, the antennas were slowly pulled upward, and a measurement was triggered every $0.05 \mathrm{~m}$. Using a temporal sampling rate of 1,526 $\mathrm{MHz}$ and a stacking rate of 32 proved to be a good compromise between signal quality and measurement speed (a complete profile of the $300 \mathrm{~m}$ borehole took roughly $45 \mathrm{~min}$ ).

The main purpose of this short contribution is to demonstrate the remarkable capabilities of such measurements for imaging changes of fracture properties. Therefore, we restrict our analyses here to the measurements performed in borehole CB1.

\section{Data Processing}

We applied a relatively standard processing sequence for obtaining static images from the data acquired. Initially, we applied a high-pass filter for removing low frequencies $(<40 \mathrm{MHz})$ that were outside of the frequency band emitted by the transmitting antenna. Next, we interpolated missing traces to guarantee a regular spatial sampling of $0.05 \mathrm{~m}$. Less than $1 \%$ of the traces were missing. Afterward, the individual traces were aligned to the arrivals of the direct wave traveling from the transmitter to the receiver antenna. This was achieved by temporal upsampling and application of cross-correlation procedures (Shakas et al., 2016). Next, a time dependent gain function was applied to account for spherical spreading and thus to enhance signal amplitudes at later times. GPR data typically include repetitive patterns that are similar on several nearby recorded traces. They include the arrival of the direct wave and so-called system ringing caused by EM waves 
(a)

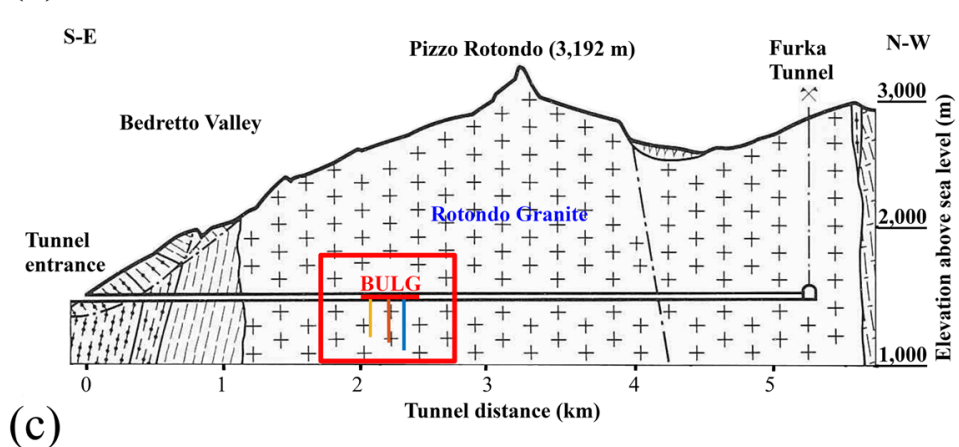

(b)

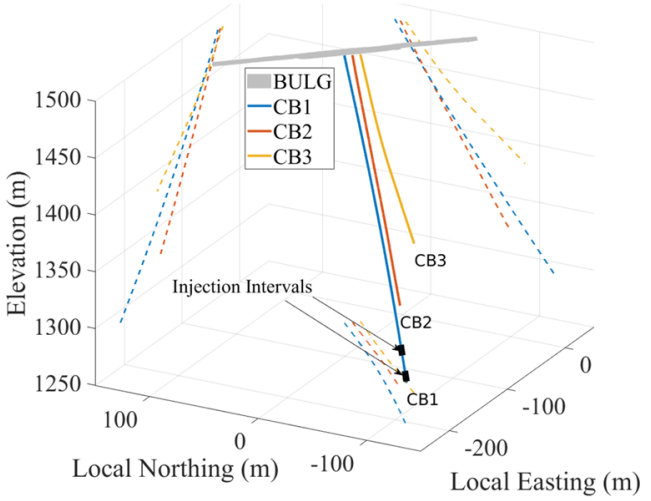

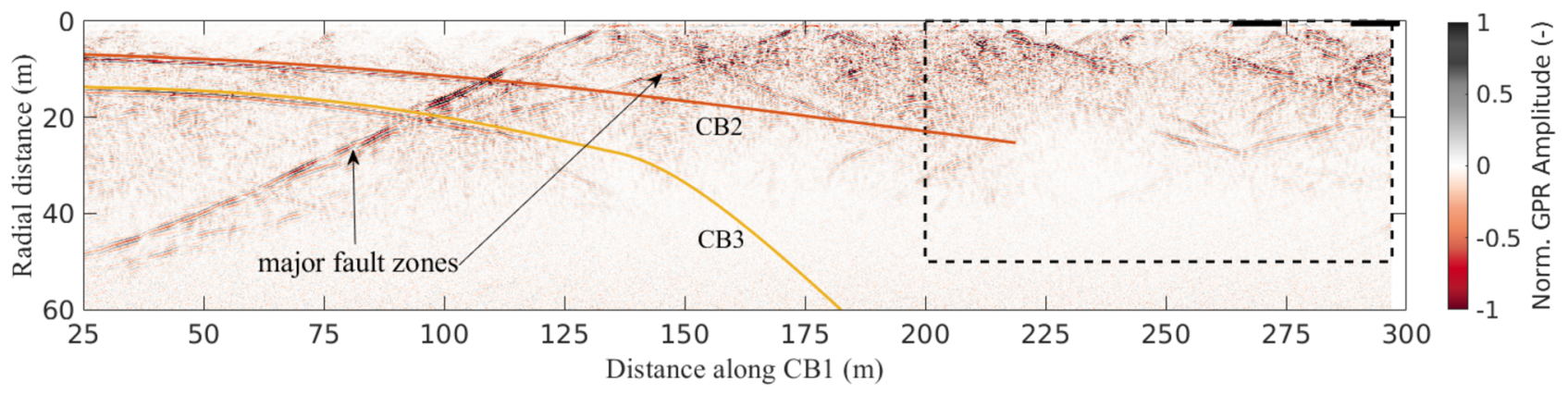

Figure 1. (a) Geological cross section of the Bedretto tunnel, modified from Keller and Schneider (1982). The section where the BULG is located is highlighted with a (red) rectangle. (b) A 3-D visualization of the existing CB boreholes in the BULG. Stimulation intervals in CB1 are denoted by black bars. (c) GPR single-hole reflection (reference) profile from CB1. As in (b), stimulation intervals are denoted by black bars. The dashed rectangle in the top right part delimits the region for which difference images were produced. The labels CB2 and CB3 indicate reflections from the other boreholes.

bouncing between the antennas and reverberating within the borehole. These features were removed by subtracting a mean trace computed over a $50 \mathrm{~m}$ moving window (corresponding to 1,000 traces). Finally, a time-to-distance conversion was applied using a GPR velocity of $0.128 \mathrm{~m} / \mathrm{ns}$. The velocity was obtained from two independent laboratory measurement techniques of dielectric properties on borehole cores.

Static images, obtained with the processing sequence described above, allow the geometry of fractures in a large volume around a borehole to be described. This is essential during an initial characterization phase, but it is equally important to identify changes in fracture properties caused by hydraulic stimulations. This can be achieved with difference images using repeated GPR surveys (Dorn et al., 2011; Giertzuch et al., 2020; Shakas et al., 2016). For fully exploiting the information content of such repeated surveys, additional processing steps are required. In addition to aligning the traces in time using the direct wave, we also aligned the entire images of two individual data sets along the borehole length. Subtle shifts between the recordings of two GPR data sets can result, for example, from cable twist. Over a distance of $300 \mathrm{~m}$, this can result in significant inconsistencies. We corrected for this by computing the 2-D cross-correlation coefficients within a range of \pm 20 traces $( \pm 1 \mathrm{~m})$. We then readjusted the two data sets such that they correlated optimally, thereby assuming that signal portions from reflectors that were not changing over time dominate over those portions being affected by temporal changes (i.e., the stimulations). The shifts applied were always less than four traces, that is, less than $0.2 \mathrm{~m}$.

Subsequently, we applied a further temporal resampling, as described in more detail by Giertzuch et al. (2020). This was necessary because of known time-varying drift in the sampling frequency of the data acquisition system. After applying these additional processing steps, we subtracted the two data sets from each other to obtain a difference image.

\section{Results}

In Figure 1c we show the postprocessed GPR data for borehole lengths $>25 \mathrm{~m}$ of the survey performed prior to the stimulation. Subsequently, we refer to this as the "reference profile." 
The region close to the borehole (approximately at radial distances up to 2 to $3 \mathrm{~m}$ away from the borehole) offers limited information. This is due to the antenna separation of $2.7 \mathrm{~m}$, and the removal procedure of the direct wave. At lengths down to about $130 \mathrm{~m}$, reflections originating from the other boreholes CB2 and CB3 can be recognized clearly at distances up to $30 \mathrm{~m}$ away from CB1. Fractures intersecting borehole CB1 appear as chevron-type patterns (e.g., Olsson et al., 1992). The region below 140 $\mathrm{m}$ is highly fractured, with several zones of water inflow, which was measured by hydraulic screening. The most prominent fault zone intersects the borehole at about $145 \mathrm{~m}$. It can be traced more than $50 \mathrm{~m}$ away from the borehole and with a total length of more than $200 \mathrm{~m}$, but it lies outside of the area possibly affected by the stimulation (indicated by the dashed rectangle in Figure 1c).

Fractures intersecting the borehole in this region, as observed from acoustic borehole logs, are marked with green crosses.

An enlarged version of this area is depicted in Figure 2a. It includes several features that could be activated by the stimulations that are labeled from F1 to F10. In the following, we call these features, but they can be interpreted as water-filled fractures. All features (fractures) intersecting borehole CB1 could be verified with borehole acoustic and borehole image tools. Figures $2 b$ and $2 c$ show the same portions of the GPR sections obtained from the two repeat surveys. By visual comparison of the three panels in Figure 2, it is difficult to identify any differences. Therefore, we focus the discussion on the difference images shown in Figure 3. Since the differences are much weaker than the original reflections, the amplitude scaling used here is only half of that used in Figures 1 and 2. To highlight that these are time-lapse changes (differences) and not static profiles, we also use a different coloring scheme.

For appraising the reliability of the difference images, it is worth mentioning that boreholes CB2 and CB3 were empty while recording the reference profile. During the first repeat survey, there was a copper heating cable installed in $\mathrm{CB} 2$, and during the second repeat survey, there was a packer system installed with metallic rods until the bottom length in CB2. These two changes make the borehole trajectory visible in the difference images.

As an additional test of the reliability of our data and data processing procedures, we conducted a fourth GPR survey immediately ( $<2 \mathrm{hr}$ ) after completing the second repeat survey. During such a short time span, no changes are expected to occur in the fractured system. Indeed, the difference image between this additional measurement and the second repeat survey did not show any significant changes in reflection strengths (image is available in the supporting information).

Combined analysis of the static images in Figure 2 and the difference images in Figure 3 allows distinguishing between features that were affected by the stimulations (marked green in Figure 3 ) and those that remained unaffected (marked black in Figure 3). Before discussing the individual features, we would like to highlight an important limitation of single-hole GPR surveying, as employed in this study. The transmitter antenna radiates energy in all directions. Likewise, the receiver antenna captures signals from all directions. This results in an azimuthal ambiguity. That is, we can determine the distance away from the borehole from a reflecting feature, and for planar structures, such as fractures, we can determine the dip relative to the borehole trajectory. However, the azimuth relative to the borehole trajectory cannot be resolved.

F2 and F3 appear as relatively strong reflectors in the static images, but they are hardly affected by the stimulation. As expected, the majority of the affected features is located near the stimulation intervals, but there are also important exceptions. For example, F1 is a long fracture that intersects the shallower injection interval and extends to the left margin of the images. It appears to be only slightly altered by the stimulation, but changes can be observed at lengths of $200 \mathrm{~m}$ and distances of up to $30 \mathrm{~m}$ away from the borehole.

One would expect that fractures intersecting the stimulation intervals would show the most prominent changes. Feature F10 originates from a fracture connecting to the shallower stimulation interval. Interestingly enough, in the difference image of the first repeat survey it is hardly visible, but it exhibits a stronger signature in the difference image of the second repeat survey.

Features F5, F6, F7, and F8 show strong reflections in the static images, and they can be traced to radial distances of $35 \mathrm{~m}$. They are also clearly visible in both difference images, whereby the reflection strengths increased visibly from the first to the second repeat survey. It is interesting to note that none of these features has a visible connection to the stimulation intervals. 

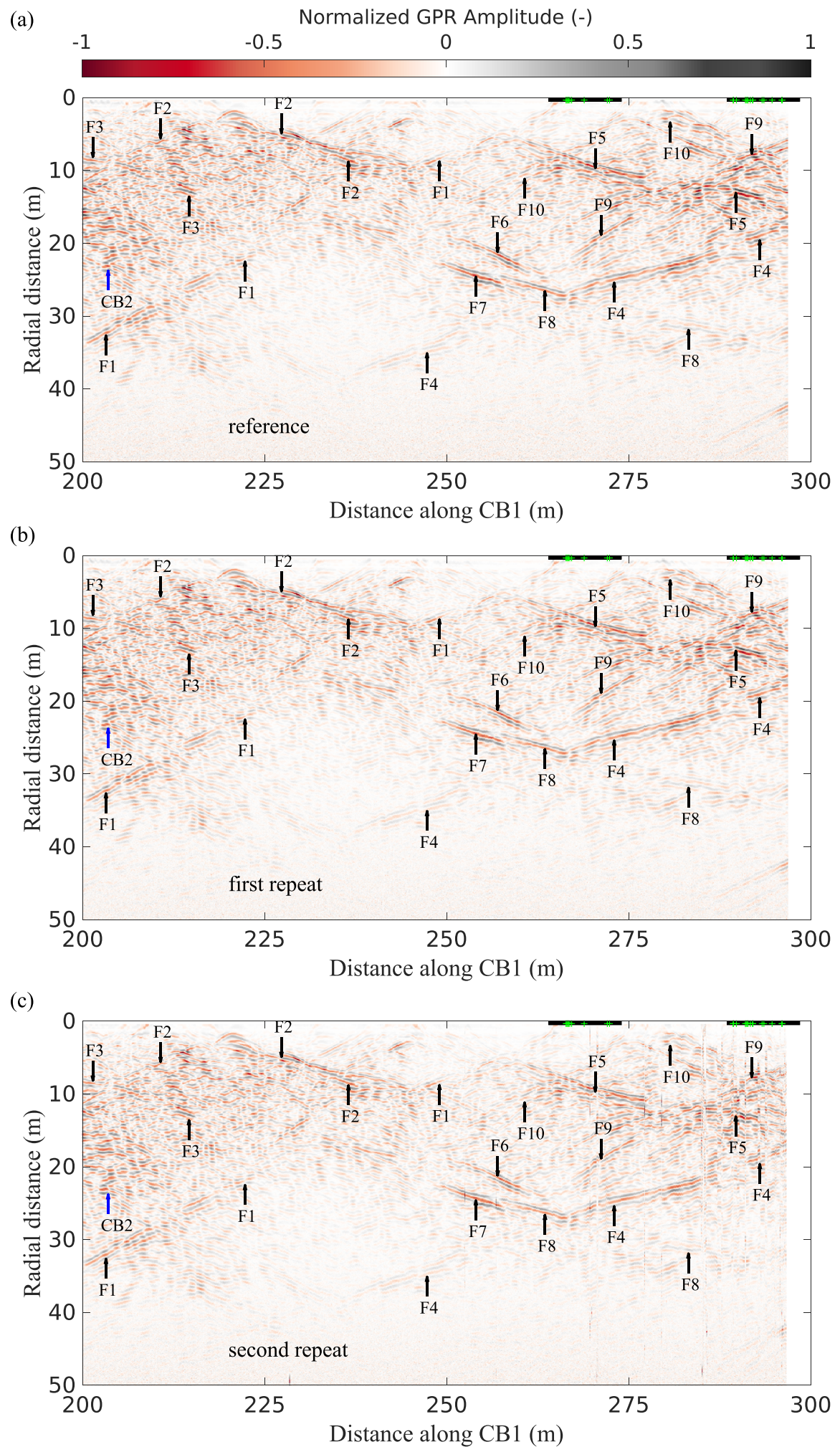

Figure 2. Reference (a) as well as first (b) and second (c) GPR profiles, repeated 5 and 12 days (respectively) after the stimulation. Several features are mapped on this image with labels (F1 to F10), which are referenced later with respect to which are enhanced post stimulation. The packer intervals used during stimulation are shown with the filled rectangles on the top right of the figure. Fractures intersecting the borehole in this region, as observed from acoustic borehole logs, are marked with green crosses. 

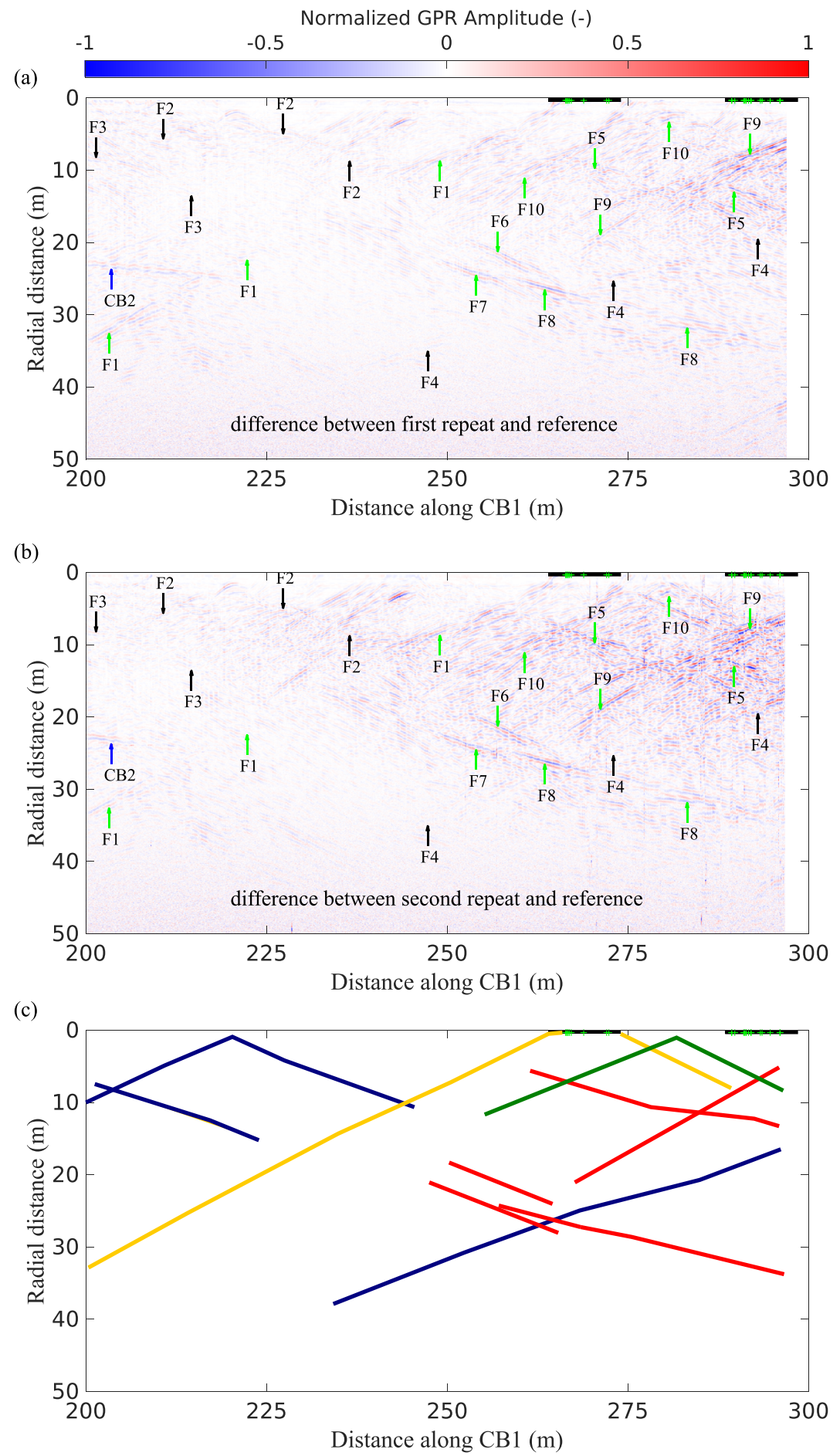

Figure 3. Difference images post-stimulation, showing the changes with respect to the reference for the first (a) and second (b) repeated profiles (compare with Figure 2). The features that are seen enhanced poststimulation are marked with green arrows (F1, F5, F6, F7, F8, F9, and F10). The reflection from borehole CB2 is now visible. In (c) we present an interpretation of our observations by drawing colored lines at the onset of the fracture reflections. The color scheme corresponds to blue $=$ no changes, yellow $=$ small changes, red $=$ strong changes, and green $=$ time-varying changes observed. 
Surprisingly, F4 is also not affected, even though it seems to directly intersect the region where several other features (F5 to F8) are affected. Due to the azimuthal ambiguity of the GPR data, it might be possible that F4 has no direct physical connection to features F5 to F8.

F9 enters the stimulated volume from greater depths. It appears enhanced post stimulation. This suggests that there is a hydraulic connection that reaches beyond the visible range of our survey, and it is part of the fracture network involved during the stimulation experiments.

\section{Discussion}

Changes in GPR reflectivity, as observed in the difference images, correspond to changes in electric properties in the rock mass. In an electrically resistive environment, such as a granitic host rock, the dielectric permittivity is the most important property, which is governed primarily by the presence or absence of water (e.g., Tsoflias et al., 2001). Therefore, the GPR results indicate primarily an increased water content in the fractured rock and they are consistent with an increase in fracture aperture. In the supplementary material we include a plot that shows the expected GPR-reflected amplitude as a function of fracture aperture, keeping all other parameters constant. While this supports that observed changes correspond to aperture variations, they are not necessarily an indication of an increase in hydraulic permeability. Nevertheless, since changes are seen relatively far away from the injection interval, there is strong evidence that a permeability change allowed the injected water to reach these regions. Therefore, the features observed in the reflection images can be equivalently identified as water-filled fractures.

An interesting observation in our difference images in Figure 3 is the generally increased reflection strength after the second repeat survey (Figure 3b), compared with the first repeat survey (Figure 3a). This indicates that the fracture network is not reacting instantaneously to the stimulations. A detailed interpretation of the possible causes requires further examination and incorporation of independent information, such as hydraulic and passive seismic data. Still, the evidence here supports that deeper portions of the reservoir have been "unlocked" from the stimulation which may lead to a delayed pressure response and upward water flow toward the borehole and tunnel.

Moreover, an electrical conductivity profile of the borehole fluid revealed that there is an increase in conductivity of the fluid in the bottom of the borehole, possibly resulting from inflow arising from deeper parts of the reservoir. Even though this increase is minor (from 712 to $860 \mu \mathrm{S} / \mathrm{m}$ ), it will still naturally lead to an overall increase in GPR reflectivity. Such an effect is undesirable, since it is not easy to decouple amplitude changes due to aperture and/or conductivity variations. Nevertheless, for the small increase in electrical conductivity observed in the borehole fluid before and after our experiments we expect the change in reflection amplitude to be only minor. We present this expected change, using analytic solutions for the thin-bed reflection coefficients (e.g., Deparis \& Garambois, 2009), in Figure S2 in the supporting information.

The changes observed in the difference images are summarized in Figure 3c. It is evident from this figure that reflection GPR is mainly sensitive to apertures that are subparallel to the borehole axis, and can provide length estimates for these fractures, as well as position them radially with respect to the borehole. Such information can be very useful for conditioning a DFN (e.g., Dorn et al., 2013). However, a detailed analysis of what these reflectivity changes correspond to in terms of absolute aperture changes requires an more extensive study which is beyond the scope of the current manuscript (e.g., Shakas et al., 2018). A combination of the latter two approaches can lead to very informative constraints for resolving the site-specific DFN.

Compared to traditional borehole logging techniques, single-hole GPR offers information at much larger radial distances away from the borehole. This is key during the characterization phase of an EGS reservoir, but this amenable property is already well known and documented in several studies (e.g., Spillmann et al., 2007). The novelty from our contribution is proof that single-hole GPR measurements can provide high-resolution spatial and temporal monitoring of changes in fracture properties. This suggests that a hydraulic stimulation process can be characterized and monitored to unprecedented resolution. In fact, the images of the fracture pattern activated by the test stimulations in BULG provided quite unexpected results.

Despite the very encouraging results from our study, there are a few issues that need to be addressed before single-hole GPR surveys can be performed in actual EGS reservoirs. First of all, appropriate measuring 
devices need to be developed that can withstand the high temperatures and pressures at greater depths. This is a technological constraint that can be directly addressed. Furthermore, the problem of the azimuthal ambiguity needs to be resolved. This can be achieved with directional antennas, and/or single-hole surveys from several boreholes need to be combined for obtaining a more unique interpretation.

\section{Conclusions}

We have presented results from a time-lapse GPR study of two hydraulic stimulation experiments that took place in a deep underground laboratory. Application of a suitable processing sequence allowed high-resolution difference images to be obtained, with which we could distinguish between fractures whose permeability was enhanced due to the stimulations, and those that remained unaffected. The changes suggest an increase in permeability that allowed for the injected water to reach fractures located tens of meters away from the borehole. Our findings suggest that there is an interaction of a complex fracture network that governs the observed changes. Fractures that are as far as $35 \mathrm{~m}$ away from the injection borehole were stimulated, and there seems to be a hydraulic connection to larger parts of the rock volume, which cannot be imaged in such detail with any other technique. These findings are key for a better understanding of the overall geometry of the fracture network and its response to hydraulic stimulations. We judge that our results represent a major advance in characterizing and monitoring the permeability evolution of EGS reservoirs. This will hopefully help to overcome some of the problems that have precluded EGS so far to be successful.

\section{Data Availability Statement}

All data and source code are available on the ETH Zurich open data repository (https://doi.org/10.3929/ ethz-b-000432225).

\section{Acknowledgments}

The BULG is established by members the Swiss Competence Center for Energy Research-Supply of Electricity (SCCER-SoE) that are supported by Innosuisse. The infrastructure of the facility is financed by ETH Immobilien. The BULG experiments are funded by the Swiss Federal Office of Energy (SFOE) (project VALTER), by the EU Horizon 2020 (project DESTRESS), by the EU initiative Geothermica-Era Net (project ZoDrEx), and the Werner von Siemens Stiftung (project MISS). The Bedretto tunnel is property of the Matterhorn Gotthard Bahnen (MGB). The stimulation work of Geo-Energie Suisse is part of the Horizon 2020 EU project DESTRESS (Demonstration of soft stimulation treatments of geothermal reservoirs) and was supported by the Swiss State Secretariat for Education, Research and Innovation (SERI) under Contract 15.0316-1. The opinions expressed and arguments employed herein do not necessarily reflect the official views of the Swiss Government. We would like to thank Prof. Dr. George Tsoflias and an anonymous reviewer for their insightful comments that helped strengthen this manuscript.

\section{References}

Abdelfettah, Y., Sailhac, P., Larnier, H., Matthey, P.-D., \& Schill, E. (2018). Continuous and time-lapse magnetotelluric monitoring of low volume injection at Rittershoffen geothermal project, northern Alsace-France. Geothermics, 71, 1-11.

Amann, F., Gischig, V., Evans, K., Doetsch, J., Jalali, R., Valley, B., et al. (2018). The seismo-hydromechanical behavior during deep geothermal reservoir stimulations: Open questions tackled in a decameter-scale in situ stimulation experiment. Solid Earth, 9(1), 115-137.

Börner, J. H., Bär, M., \& Spitzer, K. (2015). Electromagnetic methods for exploration and monitoring of enhanced geothermal systems-A virtual experiment. Geothermics, 55, 78-87.

Calò, M., Dorbath, C., \& Frogneux, M. (2014). Injection tests at the EGS reservoir of Soultz-sous-Forêts: Seismic response of the GPK4 stimulations. Geothermics, 52, 50-58.

Charléty, J., Cuenot, N., Dorbath, C., \& Dorbath, L. (2006). Tomographic study of the seismic velocity at the Soultz-sous-Forêts EGS/HDR site. Geothermics, 35(5-6), 532-543.

Cladouhos, T. T., Petty, S., Nordin, Y., Moore, M., Grasso, K., Uddenberg, M., et al. (2013). Microseismic monitoring of Newberry volcano EGS demonstration. In Proceedings of the 38th workshop on geothermal reservoir engineering, Stanford, CA: Standford University, pp. 11-13.

Council, N. R. (1996). Rock fractures and fluid flow: Contemporary understanding and applications. Washington, DC: National Academies Press. https://doi.org/10.17226/2309 Hot Dry Rock reservoir-2000 using induced microseismicity. Journal of Geophysics and Engineering, 1(1), 77-83.

Deparis, J., \& Garambois, S. (2009). On the use of dispersive APVO GPR curves for thin-bed properties estimation: Theory and application to fracture characterization. Geophysics, 74(1), J1-J12.

Doetsch, J., Gischig, V. S., Villiger, L., Krietsch, H., Nejati, M., Amann, F., et al. (2018). Subsurface fluid pressure and rock deformation monitoring using seismic velocity observations. Geophysical Research Letters, 45, 10,389-10,397. https://doi.org/10.1029/2018GL079009

Dorbath, L., Cuenot, N., Genter, A., \& Frogneux, M. (2009). Seismic response of the fractured and faulted granite to massive water injection at $5 \mathrm{~km}$ depth at Soultz-sous-Forêts (France). Geophysical Journal International, 177, 653-675.

Dorn, C., Linde, N., Borgne, T. L., Bour, O., \& de Dreuzy, J.-R. (2013). Conditioning of stochastic 3-D fracture networks to hydrological and geophysical data. Advances in Water Resources, 62, 79-89. https://doi.org/10.1016/j.advwatres.2013.10.005

Dorn, C., Linde, N., Doetsch, J., Le Borgne, T., \& Bour, O. (2012). Fracture imaging within a granitic rock aquifer using multiple-offset single-hole and cross-hole GPR reflection data. Journal of Applied Geophysics, 78, 123-132.

Dorn, C., Linde, N., Le Borgne, T., Bour, O., \& Baron, L. (2011). Single-hole GPR reflection imaging of solute transport in a granitic aquifer. Geophysical Research Letters, 38, L08401. https://doi.org/10.1029/2011GL047152

Fridleifsson, I. B. (2001). Geothermal energy for the benefit of the people. Renewable and Sustainable Energy Reviews, 5(3), $299-312$.

Giertzuch, P.-L., Doetsch, J., Jalali, M., Shakas, A., Schmelzbach, C., \& Maurer, H. (2020). Time-lapse GPR difference reflection imaging of saline tracer flow in fractured rock. Geophysics, 85(3), 1-47.

Häge, M., Blascheck, P., \& Joswig, M. (2013). EGS hydraulic stimulation monitoring by surface arrays-location accuracy and completeness magnitude: The Basel Deep Heat Mining Project case study. Journal of Seismology, 17(1), 51-61.

Hirschberg, S., Wiemer, S., \& Burgherr, P. (2015). Energy from the Earth: Deep geothermal as a resource for the future? (Vol. 62). Zurich, Switzerland: vdf Hochschulverlag AG. https://www.research-collection.ethz.ch/handle/20.500.11850/91855
Delepine, N., Cuenot, N., Rothert, E., Parotidis, M., Rentsch, S., \& Shapiro, S. A. (2004). Characterization of fluid transport properties of the 
Jalali, M., Gischig, V., Doetsch, J., Näf, R., Krietsch, H., Klepikova, M., et al. (2018). Transmissivity changes and microseismicity induced by small-scale hydraulic fracturing tests in crystalline rock. Geophysical Research Letters, 45, 2265-2273. https://doi.org/10.1002/ 2017GL076781

Jeanne, P., Rutqvist, J., Hutchings, L., Singh, A., Dobson, P. F., Walters, M., et al. (2015). Degradation of the mechanical properties imaged by seismic tomography during an EGS creation at The Geysers (California) and geomechanical modeling. Physics of the Earth and Planetary Interiors, 240, 82-94.

Jeanne, P., Rutqvist, J., Rinaldi, A. P., Dobson, P. F., Walters, M., Hartline, C., \& Garcia, J. (2015). Seismic and aseismic deformations and impact on reservoir permeability: The case of EGS stimulation at The Geysers, California, USA. Journal of Geophysical Research: Solid Earth, 120, 7863-7882. https://doi.org/10.1002/2015JB012142

Julian, B. R., Foulger, G. R., \& Monastero, F. C. (2009). Seismic monitoring of EGS stimulation tests at the Coso geothermal field, California, using microearthquake locations and moment tensors. In Thirty-fourth workshop on geothermal reservoir engineering, Stanford University, Stanford, California, February, pp. 9-11.

Keller, F., \& Schneider, T. R. (1982). Geologie und Geotechnik. Schweizer Ingenieur und Architekt, 100(24), 512-520.

Klimczak, C., Schultz, R. A., Parashar, R., \& Reeves, D. M. (2010). Cubic law with aperture-length correlation: Implications for network scale fluid flow. Hydrogeology Journal, 18(4), 851-862.

MacFarlane, J., Thiel, S., Pek, J., Peacock, J., \& Heinson, G. (2014). Characterisation of induced fracture networks within an enhanced geothermal system using anisotropic electromagnetic modelling. Journal of Volcanology and Geothermal Research, $288,1-7$.

Markovaara-Koivisto, M., Hokkanen, T., \& Huuskonen-Snicker, E. (2014). The effect of fracture aperture and filling material on GPR signal. Bulletin of Engineering Geology and the Environment, 73(3), 815-823.

Nicholl, M. J., Rajaram, H., Glass, R. J., \& Detwiler, R. (1999). Saturated flow in a single fracture: Evaluation of the Reynolds equation in measured aperture fields. Water Resources Research, 35(11), 3361-3373.

Olsson, O., Falk, L., Forslund, O., Lundmark, L., \& Sandberg, E. (1992). Borehole radar applied to the characterization of hydraulically conductive fracture zones in crystalline rock. Geophysical Prospecting, 40(2), 109-142.

Oron, A. P., \& Berkowitz, B. (1998). Flow in rock fractures: The local cubic law assumption reexamined. Water Resources Research, 34(11), 2811-2825.

Peacock, J. R., Thiel, S., Reid, P., \& Heinson, G. (2012). Magnetotelluric monitoring of a fluid injection: Example from an enhanced geothermal system. Geophysical Research Letters, 39, L18403. https://doi.org/10.1029/2012GL053080

Rutledge, J. T., \& Phillips, W. S. (2003). Hydraulic stimulation of natural fractures as revealed by induced microearthquakes, Carthage Cotton Valley gas field, east Texas. Geophysics, 68(2), 441-452.

Shakas, A., \& Linde, N. (2017). Apparent apertures from ground penetrating radar data and their relation to heterogeneous aperture fields Geophysical Journal International, 209(3), 1418-1430.

Shakas, A., Linde, N., Baron, L., Bochet, O., Bour, O., \& Le Borgne, T. (2016). Hydrogeophysical characterization of transport processes in fractured rock by combining push-pull and single-hole ground penetrating radar experiments. Water Resources Research, 52, 938-953. https://doi.org/10.1002/2015WR017837

Shakas, A., Linde, N., Le Borgne, T., \& Bour, O. (2018). Probabilistic inference of fracture-scale flow paths and aperture distribution from hydrogeophysically-monitored tracer tests. Journal of Hydrology, 567, 305-319.

Shapiro, S.-A., \& Dinske, C. (2009). Fluid-induced seismicity: Pressure diffusion and hydraulic fracturing. Geophysical Prospecting, 57(2), 301-310.

Shapiro, S.-A., Dinske, C., \& Rothert, E. (2006). Hydraulic-fracturing controlled dynamics of microseismic clouds. Geophysical Research Letters, 33, L14312. https://doi.org/10.1029/2006GL026365

Shapiro, S.-A., Rothert, E., Rath, V., \& Rindschwentner, J. (2002). Characterization of fluid transport properties of reservoirs using induced microseismicity. Geophysics, 67(1), 212-220.

Sharp, J. M. (2014). Fractured rock hydrogeology (edn. 1). London, UK: CRC Press.

Spichak, V., \& Manzella, A. (2009). Electromagnetic sounding of geothermal zones. Journal of Applied Geophysics, 68(4), 459-478.

Spillmann, T., Maurer, H., Willenberg, H., Evans, K. F., Heincke, B., \& Green, A. G. (2007). Characterization of an unstable rock mass based on borehole logs and diverse borehole radar data. Journal of Applied Geophysics, 61(1), 16-38.

Thiel, S. (2017). Electromagnetic monitoring of hydraulic fracturing: Relationship to permeability, seismicity, and stress. Surveys in Geophysics, 38(5), 1133-1169.

Tsoflias, G. P., Halihan, T., \& Sharp, J. M. Jr. (2001). Monitoring pumping test response in a fractured aquifer using ground-penetrating radar. Water Resources Research, 37(5), 1221-1229.

Tsoflias, G. P., \& Hoch, A. (2006). Investigating multi-polarization GPR wave transmission through thin layers: Implications for vertical fracture characterization. Geophysical Research Letters, 33, L20401. https://doi.org/10.1029/2006GL027788

Tsoflias, G. P., Perll, C., Baker, M., \& Becker, M. W. (2015). Cross-polarized GPR imaging of fracture flow channeling. Journal of Earth Science, 26(6), 776-784.

Vogt, C., Marquart, G., Kosack, C., Wolf, A., \& Clauser, C. (2012). Estimating the permeability distribution and its uncertainty at the EGS demonstration reservoir Soultz-sous-Forêts using the ensemble Kalman filter. Water Resources Research, 48, W08517. https://doi.org/ 10.1029/2011WR011673

Witherspoon, P. A., Wang, J. S. Y., Iwai, K., \& Gale, J. E. (1980). Validity of cubic law for fluid flow in a deformable rock fracture. Water Resources Research, 16(6), 1016-1024. 